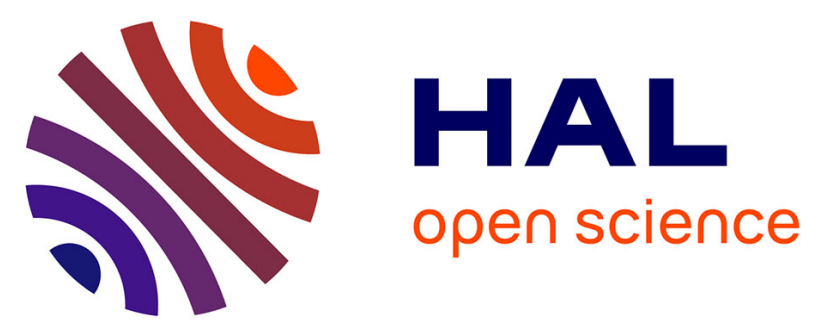

\title{
Biocomposite films based on poly(lactic acid) and chitosan nanoparticles: elaboration, microstructural and thermal characterization
}

Nibal Hijazi, Nicolas Le Moigne, Élisabeth Rodier, Martial Sauceau, Thierry Vincent, Jean-Charles Bénézet, Jacques Fages

\section{To cite this version:}

Nibal Hijazi, Nicolas Le Moigne, Élisabeth Rodier, Martial Sauceau, Thierry Vincent, et al.. Biocomposite films based on poly(lactic acid) and chitosan nanoparticles: elaboration, microstructural and thermal characterization. Polymer Engineering and Science, 2019, 59 (s1), pp.E350-E360. 10.1002/pen.24983 . hal-01924005

\section{HAL Id: hal-01924005 https://imt-mines-albi.hal.science/hal-01924005}

Submitted on 27 Nov 2018

HAL is a multi-disciplinary open access archive for the deposit and dissemination of scientific research documents, whether they are published or not. The documents may come from teaching and research institutions in France or abroad, or from public or private research centers.
L'archive ouverte pluridisciplinaire HAL, est destinée au dépôt et à la diffusion de documents scientifiques de niveau recherche, publiés ou non, émanant des établissements d'enseignement et de recherche français ou étrangers, des laboratoires publics ou privés. 


\title{
Biocomposite Films Based on Poly(Lactic Acid) and Chitosan Nanoparticles: Elaboration, Microstructural and Thermal Characterization
}

\author{
Nibal Hijazi, ${ }^{1,2}$ Nicolas Le Moigne ${ }^{\circ},{ }^{1}$ Elisabeth Rodier, ${ }^{2}$ Martial Sauceau, ${ }^{2}$ Thierry Vincent, ${ }^{1}$ \\ Jean-Charles Benezet, ${ }^{1}$ Jacques Fages ${ }^{2}{ }^{2}$ \\ ${ }^{1}$ C2MA, IMT Mines Alès, Université de Montpellier, 6 avenue de Clavières, 30319, Alès, Cédex, France \\ ${ }^{2}$ Centre RAPSODEE, IMT Mines Albi, Université de Toulouse, CNRS, F-81013, Albi, France
}

\begin{abstract}
Structured and fully bio-based polymer assemblies based on chitosan micro- and nano-particles and poly(lactic acid) (PLA) were developed using a continuous cast-film extrusion process. The microstructure and thermal properties of the resulting biocomposite films are studied. Dispersion and size distribution of chitosan particles within the films were analyzed by optical microscopy and laser diffraction. Results show a homogeneous dispersion with no particles agglomeration, due to favorable physico-chemical interactions between chitosan particles and PLA and weak particle cohesion within the agglomerates. Differential scanning calorimetry experiments evidence a pronounced nucleating effect as well as an enhanced crystal growth rate, and a great increase in crystallinity of PLA in the presence of chitosan particles. Furthermore, in the case of chitosan nanoparticles, no reduction of PLA molecular weight occurred as revealed by gel permeation chromatography. The dispersion of nanosized chitosan particles in PLA thus appears to be an efficient way to control its crystallization behavior without degrading its molecular characteristics.
\end{abstract}

\section{INTRODUCTION}

Structuring polymeric systems at micro- and nano-scales to control their physical properties is considered as a key issue in various domains such as packaging, construction, transportation, and biomedicine including tissue engineering. Research on the development of structured bio-based materials for these applications is very active as discussed in a recent review [1]. In this regard, poly(lactic acid) (PLA) experiences a great interest as matrix materials in packaging, pharmaceutical and biomedical applications [2-4]. PLA is a linear thermoplastic biopolyester obtained from renewable and abundant resources, mostly by fermentation of starchy materials (corn, potatoes, etc.). It has several interesting properties such as its transparency, low toxicity, biocompatibility and degradability in biological environments. However, PLA is brittle with a low crystallization rate [5], and it has a high gas permeability [6], which limits its widespread development in several technical applications.

Correspondence to: N. Le Moigne; e-mail: nicolas.le-moigne@mines-ales.fr or J. Fages; e-mail: jacques.fages@mines-albi.fr
Hence, several strategies have been proposed to control the physical properties of PLA. Solvent or melt blending with other polymers, such as (bio)polyesters, or the use of plasticizers have been widely investigated [2,6,7]. Different inorganic nanoparticulate fillers were added to PLA matrix to enhance some of its properties and to extend its applications, for instance silicates [8,9], such as montmorillonite [10]. Solid bio-based organic fillers such as wood flour, starch particles $[11,12]$ or cellulose nanocrystals and nanofibrils [13-15] were also incorporated in PLA by polymer melt blending or solvent casting. In this regard, chitosan microparticles and nanoparticles have also been considered for controlling PLA physical properties [16-18]. Chitosan is an amino-polysaccharide made of D-glucosamine and N-acetyl-Dglucosamine units and obtained by deacetylation in alkali conditions of chitin, the major component of crustacean shells and fungi cell walls. Besides being bio-based, biocompatible and biodegradable, chitosan has many assets such as its cytocompatibility, non-toxicity, high sorption capacities towards metal ions and potential antimicrobial activity [19-21]. It is therefore a biopolymer of choice for the development of functional bio-based materials for sorbents, packaging and biomedical applications, which can be used solely or in association with another biopolymer either by solvent or polymer melt blending [17].

The polymer melt blending route presents several advantages as it is a solvent free process allowing the design of complex $3 \mathrm{D}$ objects by classical plastics processes or emerging ones such as 3D printing. In this regard, Bonilla et al. [16] studied the effect of 5 and $10 \% \mathrm{w} / \mathrm{w}$ grinded chitosan micro-particles (715 and $180 \mu \mathrm{m})$ on the physical and chemical properties and antimicrobial activity of PLA-based films prepared by extrusion. They found that PLA/chitosan films were rougher, less rigid, less mechanically resistant and more permeable to water vapor than pure PLA films. No significant changes in the thermal behavior of PLA were noticed but its crystallization temperature slightly increased. An antimicrobial effect characterized by a decrease of the total count of aerobic bacterial colonies on pork meat was observed with a substantial improvement for smallest size chitosan micro-particules related to improved dispersion and surface availability towards bacteria. Correlo et al. [17] studied the behavior of 50\%/50\% w/w PLA/chitosan composites prepared by extrusion and found that the presence of chitosan micro-particles has a negative effect on PLA mechanical properties that is, a drastic decrease of strength and strain at break. This was attributed to a bad interfacial cohesion between PLA and chitosan particles and/or the hydrolysis of PLA chains during the extrusion process, induced by the moisture of chitosan particles. The authors also noticed a shift of the glass transition temperature to lower values 
related to the degradation of PLA through hydrolysis and shearinginduced chain scissions that are promoted at high loading rates of chitosan particles. Confirming the results of Bonilla et al. [16], they also observed an early crystallization of PLA that was assumed to be related either to a nucleating effect of chitosan or to the shorter length of PLA chains consecutive to degradation. Besides, Elsawy et al. [18] investigated the effect of chitosan nanoparticles $(0-5 \%$ w/ w), obtained by ionic gelation, on the physical properties of PLA based nanocomposites prepared by twin-screw extrusion and injection molding. Good dispersion of the chitosan nanoparticles was obtained. Thermal stability of the nanocomposites was slightly decreased for high amounts of chitosan nanoparticles $(5 \% \mathrm{w} / \mathrm{w})$. With amounts of chitosan nanoparticles up to $3 \% \mathrm{w} / \mathrm{w}$, mechanical properties were significantly improved. In particular, higher elongation at break and impact strength were obtained, attesting for a more ductile behavior of these nanocomposites.

The incorporation of solid chitosan particles in PLA by melt blending can thus have an influence on its microstructure and functional properties provided that particle size is controlled and good particle dispersion is achieved. To our knowledge, no comprehensive study has been carried out to understand the effect of various type and size chitosan particles on the microstructure and thermal properties of PLA biocomposites, which is of high relevance for the control of their functional properties. In this work, chitosan nanoparticles, generated by a supercritical $\mathrm{CO}_{2}$-assisted atomization and crystallization (SCASA) process [22], as well as chitosan microparticles, commercial grade and obtained by a nebulization process, were incorporated in PLA by cast-film extrusion using a micro-compounder. The effects of size and loading rate of these various chitosan particles on the microstructure and thermal properties of PLA/chitosan biocomposite films were studied. In particular, the dispersion state of chitosan particles and their influence on the crystallization behavior of PLA are analyzed and discussed.

\section{MATERIALS AND METHODS}

Materials

A film extrusion grade of PLLA (PLE003) in pellets (density of $1.25 \mathrm{~g} . \mathrm{cm}^{-3}$, melting temperature $T_{\mathrm{m}}=145-160{ }^{\circ} \mathrm{C}$; molar mass (measured by gel permeation chromatography (GPC) at the Institut Charles Gerhardt [ICG] Montpellier, France), $\overline{M n}=$ 92,135 g.mol ${ }^{-1}$ and $\overline{M w}=163,937 \mathrm{~g} \cdot \mathrm{mol}^{-1}$ and polydispersity index $=1.78$ was purchased from NaturePlast (France).

Commercial chitosan extracted from shrimp shells (Fig. 1a) was purchased from France Chitine (France). Its viscosity is about $50 \mathrm{mPa} . \mathrm{s}$ for a $1 \%(\mathrm{w} / \mathrm{w})$ chitosan/acetic acid solution at $25^{\circ} \mathrm{C}$. Acetylation degrees (DA) measured by the supplier using IR spectroscopy and by the Laboratoire d'ingénierie des matériaux polymères (IMP), Lyon, France using nuclear magnetic resonance (NMR) are $10 \%$ and $9.64 \%$, respectively. The average molecular weights measured by GPC at IMP were $\overline{M w}=152,700 \mathrm{~g} \cdot \mathrm{mol}^{-1}$ and $\overline{M n}=79,750 \mathrm{~g}$. $\mathrm{mol}^{-1}$, with a polydispersity index of 1.9. The average size of the commercial grinded chitosan microparticles was $36 \mu \mathrm{m}$.

For the generation of nebulized chitosan microparticles, an aqueous solution of acetic acid and commercial chitosan (1:1 w/w) at a concentration $C_{\mathrm{m}}=0.6 \mathrm{~g} . \mathrm{L}^{-1}$ was prepared at room temperature. This solution was then sprayed using compressed air (two bars) through a nebulizing nozzle in a sodium hydroxide $\mathrm{NaOH}$ solution $(1 \mathrm{M})$ under continuous stirring. At the end of spraying, the suspension obtained is washed several times with demineralized water and then lyophilized (CHRIST Alpha 1-4 LD 0.1 mbar $/-50^{\circ} \mathrm{C}$, Germany). The resulting chitosan microparticles (Fig. 1b and c) presented a laminated and porous aspect with a median size of $39 \pm 23 \mu \mathrm{m}$, as measured by SEM observations with a Quanta 200 FEG electron microscope (FEI, The Netherlands) and image analyzed with ImageJ software based on more than 500 measured particle diameters.

Chitosan nanoparticles (Fig. 1d and e) were generated by a SCASA process from commercial chitosan particles dissolved under continuous stirring for $48 \mathrm{~h}$ in $\mathrm{CO}_{2}$-acidified water. Further details about the SCASA process and characterization of these chitosan nanoparticles can be found in the work of Hijazi et al. [22]. Based on SEM observations and image analysis, it was found that the generated chitosan particles have a bi-modal size distribution: $(i)$ nanoscale particles with a median diameter of $390 \mathrm{~nm}(<15 \%$ of the measured particles $>1 \mu \mathrm{m})$ and (ii) microscale particles (median diameter around $20 \mu \mathrm{m}$ ) mainly composed of agglomerated nanoscale particles.

Structural analysis by X-ray diffraction [22] revealed that chitosan nanoparticles as well as microparticles produced by nebulization were less crystalline with a pronounced halo at $2 \theta \approx 23^{\circ}$ that was attributed to an allomorphic form of chitosan [23]. FT-IR spectra obtained in attenuated total reflectance mode did not reveal any differences between commercial chitosan particles and nanoparticles produced by the SCASA process, acetylation degrees being similar. Main degradation temperatures as measured by thermogravimetric analysis were $267^{\circ} \mathrm{C}, 253^{\circ} \mathrm{C}$, and $290^{\circ} \mathrm{C}-$ $297^{\circ} \mathrm{C}$ for commercial chitosan, nebulized chitosan microparticles and chitosan nanoparticles, respectively.

\section{Cast-Film Extrusion Process}

PLA pellets and chitosan micro- and nano-particles were dried at $80^{\circ} \mathrm{C}$ for $4 \mathrm{~h}$ to eliminate moisture and avoid hydrolysis of PLA during the extrusion process. Pure PLA and PLA/chitosan biocomposite films (97.6/2.4\% w/w and 90/10\% w/w) were prepared by hot-melt extrusion using a $15 \mathrm{~cm}^{3}$ twin-screw microcompounder (DSM Xplore micro-compounder, The Netherlands) equipped with an in-line film casting and air cooling system. After several preliminary tests, a screw speed of $70 \mathrm{rpm}$, a mixing time of $5 \mathrm{~min}$, a speed roll of $600 \mathrm{~mm} \cdot \mathrm{min}^{-1}$ and a uniform temperature of $180^{\circ} \mathrm{C}$ were set-up to prevent thermal degradation of PLA. Afterwards, films were conditioned at room temperature $\left(25^{\circ} \mathrm{C}\right.$, $50 \% \mathrm{RH})$. Film thickness was measured using a Palmer digital micrometer (IHM, France) to the nearest $1 / 1,000 \mathrm{~mm}$. Six random positions in each film sample were considered and thickness was found to be between 100 and $250 \mu \mathrm{m}$ for all films. The thickness of the films decreased progressively during cast extrusion. PLA and PLA/chitosan film formulations were named as follows: "Pure PLA", "PLA:Com-x\%", "PLA:Nebu-x\%", and "PLA:Nano-x\%", where Com, Nebu and Nano stand respectively for the commercial chitosan, nebulized microparticles and chitosan nanoparticles generated by SCASA process, and $\mathrm{x} \%$ represents the loading rate of chitosan particles in the biocomposite films.

\section{Characterization of PLA and PLA/chitosan Films}

\section{Microstructural Analysis: Chitosan Particles Dispersion and Size Distribution.}

A qualitative analysis of the dispersion of the different chitosan particles in PLA films after extrusion was carried out by optical microscopy (Laborlux 11 POLS, Leitz, Germany) coupled with 

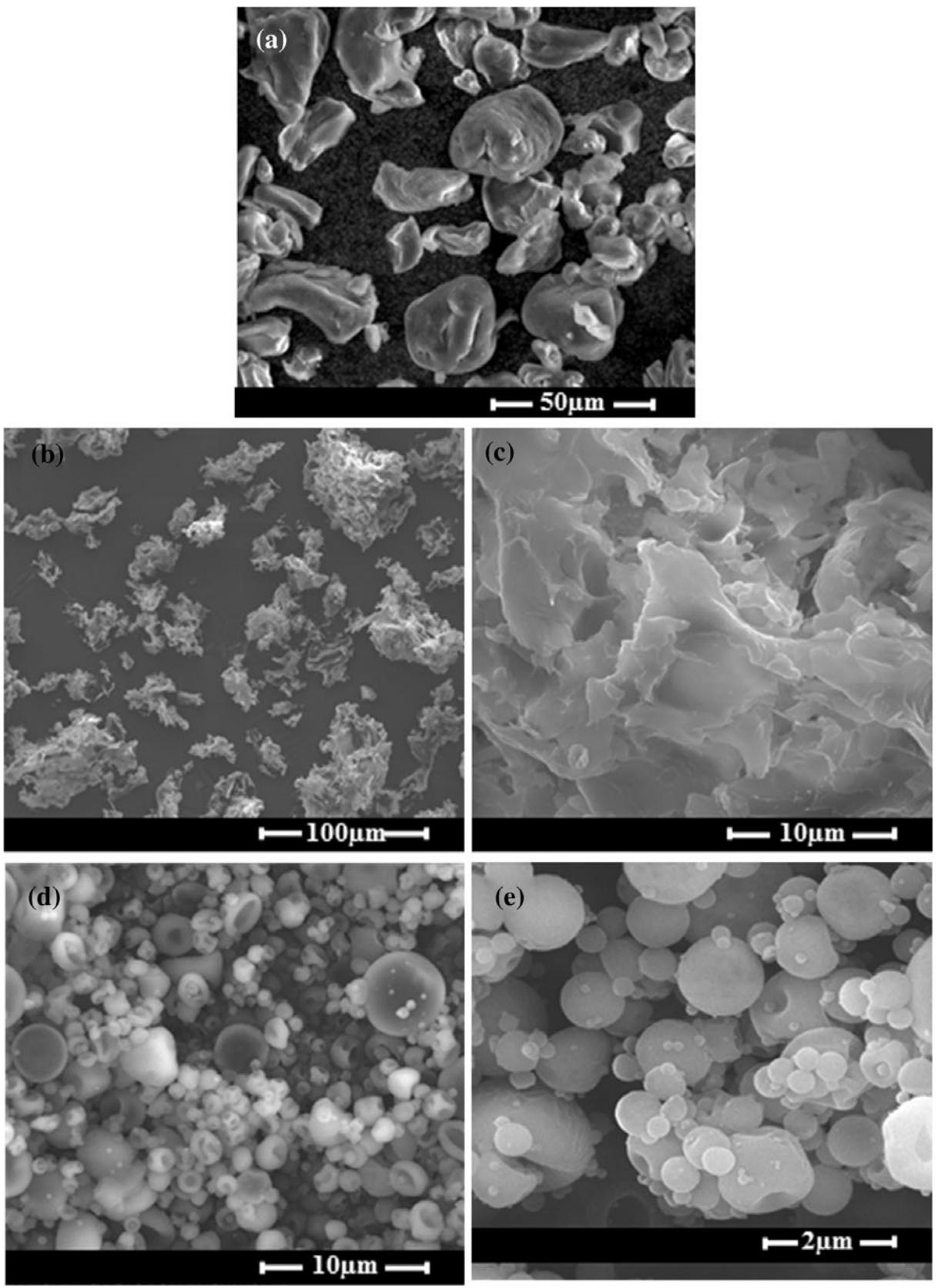

FIG. 1. SEM micrographs, at different scales, of the (a) commercial chitosan microparticles, (b, c) nebulized chitosan microparticles and (d, e) chitosan nanoparticles obtained by the SCASA process.

a mono-CDD Sony digital camera (resolution $1,600 \times 1,200$ pixels) and equipped with an image acquisition software Archimed $^{\circledR}$ (Microvision Instruments, France). A small sample of each film was placed on a preheated glass slide and melted; using a thin glass lamella, the molten sample was gently flattened in order to obtain a thin layer of material readily observable by optical microscopy in transmitted light. Additional observations under crossed polarized light with a gypsum plate were conducted on samples melted in a hot stage (Mettler FP 82 HT controlled by Mettler FP 90 central processor), then cooled at $20^{\circ} \mathrm{C} \cdot \mathrm{min}^{-1}$ and crystallized under isothermal conditions at $120^{\circ} \mathrm{C}$, so as to observe the size and shape of the PLA crystals.

In order to quantitatively analyze the size distribution of chitosan particles after extrusion, PLA / chitosan films $(1 \times 1 \mathrm{~cm})$ were dissolved into chloroform in large excess under gentle stirring for $24 \mathrm{~h}$. Using a laser diffractometer LS $13320 \mathrm{MW}$ equipped with a sonication unit (Beckman Coulter, France), chitosan particle size distribution in the PLA/chloroform mixture was determined. It should be noted that the method used has an inherent lower size limit of $400 \mathrm{~nm}$.

\section{Molecular Mass Distribution of PLA in Films.}

The molecular weights of PLA were determined by GPC at ICG (Montpellier, France). Samples of pure PLA films and PLA/ chitosan films (typically $10 \mathrm{mg}$ ) were dissolved in THF. Before injection, all mixtures were filtered through a $0.2 \mu \mathrm{m}$ filter to remove all chitosan particles and eventual insoluble fractions. GPC experiments were carried out using a Varian 390 LC-multidetector. 
The GPC was calibrated using a mix of polystyrene standards. THF was used as the eluent at a flow rate of $1 \mathrm{ml}^{\mathrm{min}}{ }^{-1}$. The weight and number average molecular weights, $\overline{M w}$ and $\overline{M n}$, respectively, and the viscometric, peak molecular and Z-average weights, $\overline{M v}, \overline{M p}$, and $\overline{M z}$ respectively, as well as the polydispersity index Ip of PLA were determined from pure PLA films and PLA/chitosan films.

Melting and Crystallization Kinetics of PLA and PLA/Chitosan Films.

Non-Isothermal Analysis

A differential scanning calorimeter (Diamond differential scanning calorimetry [DSC], PerkinElmer, USA) was used to characterize the melting and crystallization behavior of the biocomposite films. Samples weighted between 8 and $15 \mathrm{mg}$. Heating and cooling thermograms were obtained between $30^{\circ} \mathrm{C}$ and $180^{\circ} \mathrm{C}$ with a heating rate of $10^{\circ} \mathrm{C} \cdot \mathrm{min}^{-1}$ in nitrogen gas stream of $20 \mathrm{~cm}^{3}$. $\min ^{-1}$. A second heating was also performed on the samples so as to erase the thermo-mechanical history of the films. The glass transition temperature $T_{\mathrm{g}}$, the melting and cold crystallization temperatures $\left(T_{\mathrm{m}}, T_{\mathrm{cc}}\right)$, the melting and cold-crystallization enthalpies $\left(\Delta H_{\mathrm{f}}\right.$, $\left.\Delta H_{\mathrm{cc}}\right)$ were determined. Thus, the initial degree of crystallization $\chi_{c o}$ of the films after extrusion but before the cold-crystallization has occurred and the final degree of crystallization $\chi_{c f}$ after the cold crystallization can be obtained using Eqs. 1 and 2, respectively:

$$
\begin{gathered}
\chi_{c 0}=\frac{\Delta H_{\mathrm{f}}-\Delta H_{\mathrm{cc}}}{\Delta H_{f}^{0} * w_{\mathrm{PLA}}} * 100 \\
\chi_{c f}=\frac{\Delta H_{f}}{\Delta H_{f}^{0} * w_{\mathrm{PLA}}} * 100
\end{gathered}
$$

where $\Delta H^{0}$ is the melting enthalpy of $100 \%$ crystalline polymer (93 $\mathrm{J.g}^{-1}$ for PLA) [24] and $w_{\mathrm{PLA}}$ is the mass fraction of PLA in the biocomposite films.

In addition to the linear non-isothermal study, a modulated DSC (Q200, TA instrument) was used to reveal hidden thermal transitions around the melting zone [25,26]. All samples firstly underwent a heating-cooling cycle to erase the thermo-mechanical history of the material. Then, a temperature ramp up to $130^{\circ} \mathrm{C}$ was applied, followed by a sinusoidal signal with a period of $60 \mathrm{~s}$ and a magnitude of roughly $0.3^{\circ} \mathrm{C}$ around a linear heating ramp of $2^{\circ} \mathrm{C}$. $\min ^{-1}$ (equivalent to one sinusoid by $2^{\circ} \mathrm{C} \cdot \mathrm{min}^{-1}$ step), up to $200^{\circ} \mathrm{C}$ under a dry nitrogen flow of $50 \mathrm{ml} \cdot \mathrm{min}^{-1}$. Three signals were obtained: the total flow (total Heat Flow) corresponding to the signal obtained by linear non-isothermal DSC, the reversible Heat Flow related to $C_{p}$ (reversing $\mathrm{HF}$ ) and the irreversible Heat Flow related to the kinetic phenomenon (non-reversing $\mathrm{HF}$ ).

\section{Isothermal Analysis}

For all samples, crystallization kinetics were analyzed with a differential scanning calorimeter (Diamond DSC, PerkinElmer, USA), starting from the molten state of the material. All samples were heated up to $200^{\circ} \mathrm{C}$ at $200^{\circ} \mathrm{C} \cdot \mathrm{min}^{-1}$ and maintained at this temperature for $3 \mathrm{~min}$ in order to erase the thermo-mechanical history of the material. Then, to reach the temperature of the isotherm, a rapid cooling step at $200^{\circ} \mathrm{C} \cdot \mathrm{min}^{-1}$ was applied to avoid eventual crystallization during cooling. Using this approach, several isotherms were studied around the cold crystallization temperature: from $108^{\circ} \mathrm{C}$ to $132^{\circ} \mathrm{C}$.

Based on Avrami theory, the crystallization kinetics can be analyzed based on the variation of the integrated exothermic peak as a function of time $t . \alpha(t)$ represents the volume fraction of materials converted into crystals at $t$ and is the ratio of the partial area calculated at $t$ over the total area of the exothermic crystallization peak. From the fraction $\alpha(t)$, Avrami exponent $n$ and the rate constant $k$ of the isothermal transformation can be obtained by the Avrami Eq. 3:

$$
\alpha(t)=1-\exp \left(-k t^{n}\right)
$$

Eq. 3 can be linearized to obtain Eq. 4, hence straight lines are obtained where $n$ is the slope and $\ln (k)$ is the intercept:

$$
\ln [-\ln (1-\alpha(t))]=\ln (k)+n \ln (t)
$$

Furthermore, an important parameter to describe the kinetics of crystallization is the crystallization half-time $t_{1 / 2}$ for which the crystalline conversion is $50 \%$. It is related to the constant $k$ as follows (Eq. 5):

$$
k=\frac{\ln (2)}{t_{1 / 2}^{n}}
$$

\section{RESULTS AND DISCUSSION}

\section{Morphology and Dispersion State of Chitosan Particles in PLA/Chitosan Biocomposites}

Independently of the type and rate of chitosan particles, yellowing and increased roughness were observed for PLA/chitosan films. During extrusion, the addition of chitosan particles made the compound less viscous and the films seemed to be more ductile than pure PLA films for equivalent processing conditions and film thickness.

The dispersion state of chitosan particles in PLA films was analyzed qualitatively by optical microscopy in transmitted light on thin sample of PLA/chitosan $2.4 \%$ films melted between two glass plates. The micrographs in Figure 2 show the dispersion of chitosan particles for PLA:Com-2.4\%, PLA:Nebu-2.4\% and PLA: Nano-2.4\% films. In overall, a good dispersion with no noticeable clustering was observed regardless the type of chitosan particles and loading rate, i.e. 2.4 or $10 \%$ w/w. Large commercial chitosan particles are easily identified in the PLA film (Fig. 2a) and their size does not appear to be altered by the extrusion process (average diameter of $36 \mu \mathrm{m}$ before extrusion). In contrast, nebulized chitosan microparticles present a random shape with many elongated particles (Fig. 2b), and the extrusion process led to a significant decrease of their size (average diameter of $39 \pm 23 \mu \mathrm{m}$ before extrusion). This can be explained by their laminated and porous structure (Fig. 1b and c), which should favor their breaking under shearing during the extrusion process. The chitosan nanoparticles generated by the SCASA process are hardly identified by optical microscopy due to their small size. Indeed, several superimposed layers of nanoparticles are observed in the sample thickness (Fig. 2e). Only few large particles of a few micrometers were observed which was attributed to the presence of remaining agglomerated nanoparticles that did not break during extrusion, 

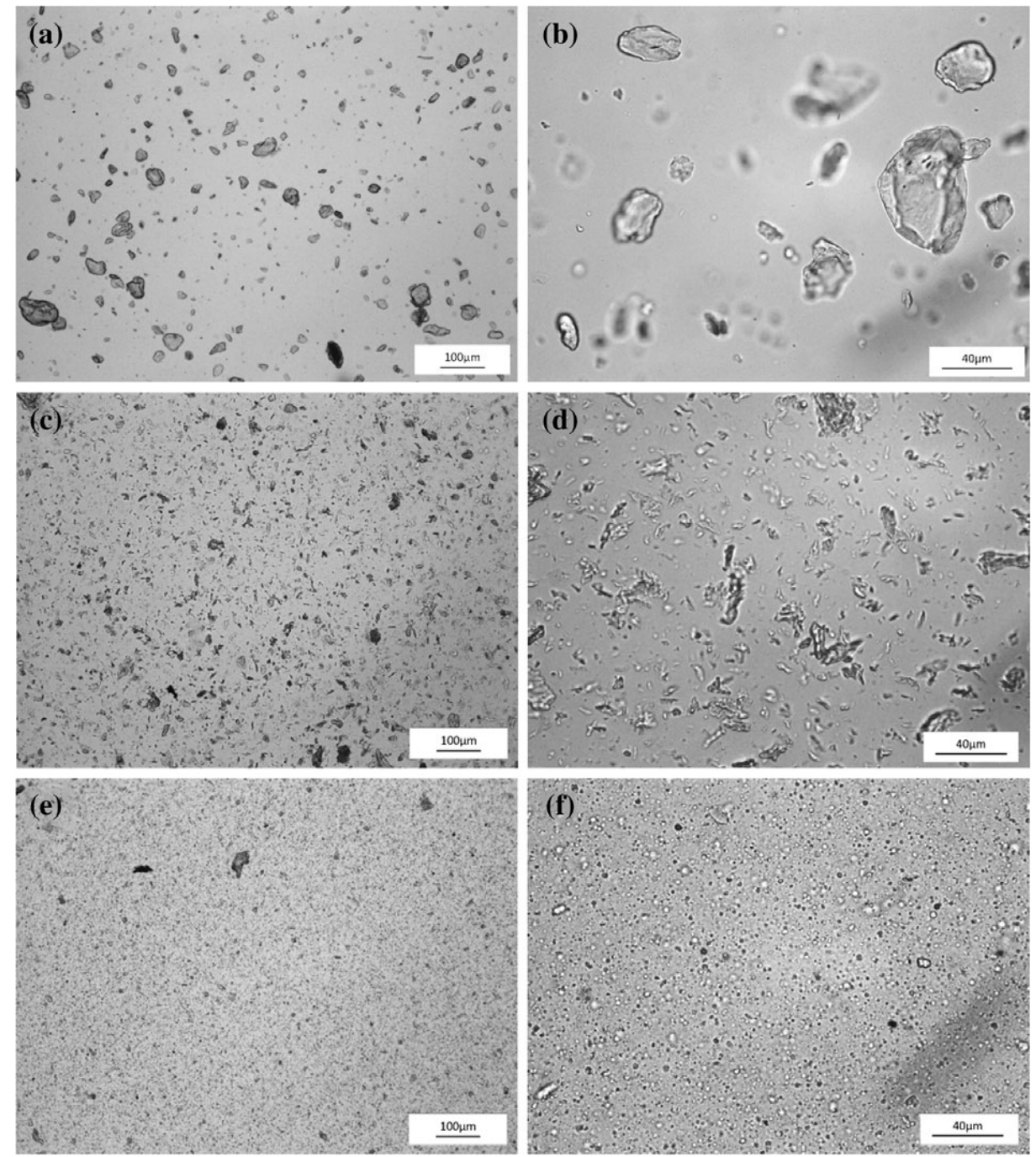

FIG. 2. Dispersion state of commercial chitosan microparticles (a, b), nebulized chitosan microparticles (c, d) and chitosan nanoparticles generated by SCASA process $(e, f)$ in PLA matrix observed by optical microscopy at two magnifications on thin sample of PLA:chitosan-2.4\% films melted between two glass plates.

and the potential presence of some impurities of residual chitosan particles from previous experiments.

As pointed out by Khoshkava and Kamal [27], the quality of dispersion in polymer-filler systems is governed by both dynamic and thermodynamic factors. During processing, the balance between externally applied shearing forces and filler-filler cohesive forces will determine the extent of dispersion. Polymer-filler interactions, characterized by the thermodynamic work of adhesion and interfacial tension, also play an important role on the dispersion quality. The thermodynamic work of adhesion $W_{\mathrm{A}}$ can be calculated from Eq. 6 derived from the OWRK [28] approach based on the geometric mean of dispersive and polar components of the surface tension of the molten polymer $\left(\gamma_{l}^{d} ; \gamma_{l}^{p}\right)$ and surface free energy of the fillers $\left(\gamma_{s}^{d} ; \gamma_{s}^{p}\right)$ :

$$
W_{A}=2\left[\sqrt{\gamma_{l}^{d} \gamma_{s}^{d}}+\sqrt{\gamma_{l}^{p} \gamma_{s}^{p}}\right]
$$

Khoshkava and Kamal [27] found dispersive and polar components of 32.5 and $8.2 \mathrm{~mJ} . \mathrm{m}^{-2}$, respectively, for PLA at $25^{\circ} \mathrm{C}$, and a surface tension thermal coefficient of $-0.06 \mathrm{~mJ} \cdot \mathrm{m}^{-2} \cdot{ }^{\circ} \mathrm{C}^{-1}$. Based on their results and considering a constant polarity ratio (the ratio of the polar component to the total surface energy), we determined dispersive and polar components of 22.4 and $5.6 \mathrm{~mJ}$. $\mathrm{m}^{-2}$ for PLA at $180^{\circ} \mathrm{C}$. Data on surface energy of chitosan are scarce and conflicting in literature. Cunha et al. [29] conducted a comprehensive study on surface energy of solid chitin and chitosan pellets and films, and found dispersive and polar components of 38.0 and $0.4 \mathrm{~mJ} . \mathrm{m}^{-2}$, respectively, for chitosan pellets (DA = $15 \%)$ at $25^{\circ} \mathrm{C}$. The authors pointed out that the DA does not affect significantly the surface energy, and highlighted the crucial role of impurities and purification procedures on the surface energy. After purification, chitosan pellets ( $\mathrm{DA}=15 \%)$ has dispersive and polar components of 33 and $18 \mathrm{~mJ} . \mathrm{m}^{-2}$, respectively. It must be noted that no data is available for surface energy of chitosan at high temperatures. Based on these literature values, we found thermodynamic work of adhesion values between PLA and solid chitosan particles of $89.8 \mathrm{~mJ}^{-2} \mathrm{~m}^{-2}$ at $25^{\circ} \mathrm{C}$ and $74.5 \mathrm{~mJ}$. $\mathrm{m}^{-2}$ at $180^{\circ} \mathrm{C}$. As a comparison, Khoshkava and Kamal [27] determine the work of adhesion between PLA and nanocrystalline 
cellulose (NCC) of $104.7 \mathrm{~mJ} . \mathrm{m}^{-2}$ at $25^{\circ} \mathrm{C}$ and roughly $44 \mathrm{~mJ} . \mathrm{m}^{-2}$ at $190^{\circ} \mathrm{C}$. With these values, appreciable dispersion quality of NCC in PLA was obtained. These authors also observed a significant decrease of the surface energy of NCC at high temperature which contributes to decrease the work of adhesion with PLA but at the same time to greatly decrease cohesive interactions between NCC particles. This led to an increase of the dispersion factor (ratio of the work of adhesion to the work of cohesion, $2 \gamma_{s}$ ), and hence an improvement of the dispersion quality.

Eventually, the calculated work of adhesion and the microscopic observations attest for the existence of favorable physico-chemical interactions between chitosan particles and PLA, and weak cohesive interactions between chitosan particles within the agglomerates, i.e. low density of Van der Waals or hydrogen bonding between individual particles (Fig. 1d and e). The shearing induced by the cast-film extrusion was thus sufficient to break the agglomerates and allow a good dispersion of the chitosan particles.

A complementary quantitative analysis of size distributions of the different chitosan particles in PLA films after extrusion was conducted by laser diffraction in liquid phase after dissolving PLA films in chloroform. As seen in Fig. 3, the commercial chitosan microparticles present an asymmetric mono-modal distribution after the extrusion process. Their median diameter is about $27 \mu \mathrm{m}$, corresponding to a specific surface of roughly $0.146 \mathrm{~m}^{2}$. $\mathrm{g}^{-1}$ (considering a density of $1.52 \mathrm{~g} . \mathrm{cm}^{-3}$ ). Considering their initial average size measured by SEM image analysis $(36 \mu \mathrm{m})$, the cast-film extrusion process did not have a significant impact on their size, which is consistent with optical microscopy observations. In contrast, the nebulized chitosan microparticles present a multi-modal distribution with three main particle diameter range centered on 2.9, 20.7, and $76.4 \mu \mathrm{m}$, corresponding to specific surfaces of $1.36 \mathrm{~m}^{2} . \mathrm{g}^{-1}, 0.19 \mathrm{~m}^{2} \cdot \mathrm{g}^{-1}$ and $0.05 \mathrm{~m}^{2} \cdot \mathrm{g}^{-1}$, respectively. This result shows that the dispersion under shearing of these microparticles occurred randomly due to their porous and laminated structure that does not allow controlling their breaking mechanisms and the resulting particle sizes during the extrusion process. In the case of chitosan nanoparticles produced by the SCASA process, the particle size distribution within the PLA film is clearly centered to smaller sizes as compared with commercial chitosan and nebulized chitosan microparticles. The distribution is

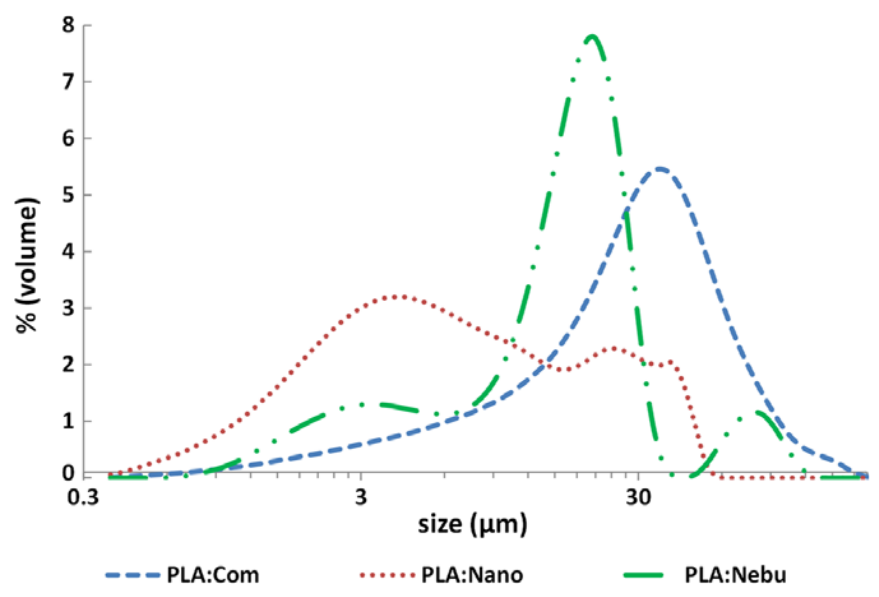

FIG. 3. Volume weighted size distribution of chitosan particles in PLA: Com, PLA:Nano and PLA:Nebu films as measured by laser diffraction in liquid phase after dissolution of PLA/chitosan films in chloroform. [Color figure can be viewed at wileyonlinelibrary.com] wide with a median diameter of $5.6 \mu \mathrm{m}$, corresponding to a specific surface of $0.70 \mathrm{~m}^{2} \cdot \mathrm{g}^{-1}$. Unfortunately, the analysis did not allow to measure particle size below $400 \mathrm{~nm}$ which should have shifted even more the distribution to smaller sizes. If considering that the clusters of chitosan nanoparticles (Fig. 1d and e) were efficiently dispersed (Fig. 2e and f) to reach the average diameter of individual nanoparticles that is, $390 \mathrm{~nm}$, then the expected specific surface would be $10.1 \mathrm{~m}^{2} \cdot \mathrm{g}^{-1}$ that is, roughly 70 times more than the one obtained with the dispersion of commercial chitosan particles, thus considerably enhancing interfacial area and interactions between PLA and chitosan particles.

In conclusion, the generation of micro- and nano-sized chitosan particles by nebulization and SCASA processes allows improving significantly the dispersion quality of chitosan particles within PLA films, due to weak cohesive interactions between chitosan particles and favorable physico-chemical interactions between PLA and chitosan as revealed by the calculation of work of adhesion. Furthermore, the dispersion of these particles offers considerably enhanced interfacial area and interactions with PLA as compared with commercial chitosan particles.

\section{Non-Isothermal Crystallization Behavior of PLA/Chitosan Biocomposites}

The effect of processing conditions and the influence of the type and loading rate of chitosan particles on the crystallization behavior of biocomposite films were investigated through non-isothermal and isothermal DSC scans, so as to study their temperature, and degree of crystallization as well as their crystallization kinetics.

Figure 4 shows the first and the second DSC heating scans as well as the cooling scans of the studied PLA/chitosan films. The thermal behavior observed during the first heating scan is related to the processing conditions and the presence of chitosan particles; whereas the second heating scan is only affected by the presence of chitosan particles since the effect of extrusion process and the thermo-mechanical history of the films were erased and normalized after the first melting and cooling. PLA has a slow crystallization rate, explaining why no exothermic peak is observed on cooling thermograms (Fig. 4b) but only appeared on heating thermograms. In fact, the cooling rate $\left(10^{\circ} \mathrm{C} / \mathrm{min}\right)$ is too fast to allow nucleation and growth of PLA crystals whereas the molecular mobility is more and more reduced by cooling; thus, a further heating allows enough molecular mobility for crystal growth. This phenomenon is known as the "cold-crystallization" often observed for (bio)polyester matrices [30].

\section{Effect of Cast-Film Extrusion Process.}

All data related to the first and second heating scans are shown in Table 1. The weight fraction of chitosan particles in the biocomposite films was taken into account for the calculation of different enthalpies. The degree of crystallinity $\chi_{c o}$ of PLA and PLA/chitosan after the extrusion process was evaluated according to Eq. 1. The results show that for pure PLA and all biocomposite films, $\chi_{c o}$ did not exceed 3\% (except for PLA:Nano-10\% and PLA:Nebu-10\%, it was around 5.5\%), indicating that all the studied materials were almost amorphous after the cast-film extrusion process. The cooling rate was indeed too fast to allow the crystallization of the films upon processing. Comparing the first and second heating scans allows analyzing the effect of the processing conditions. 

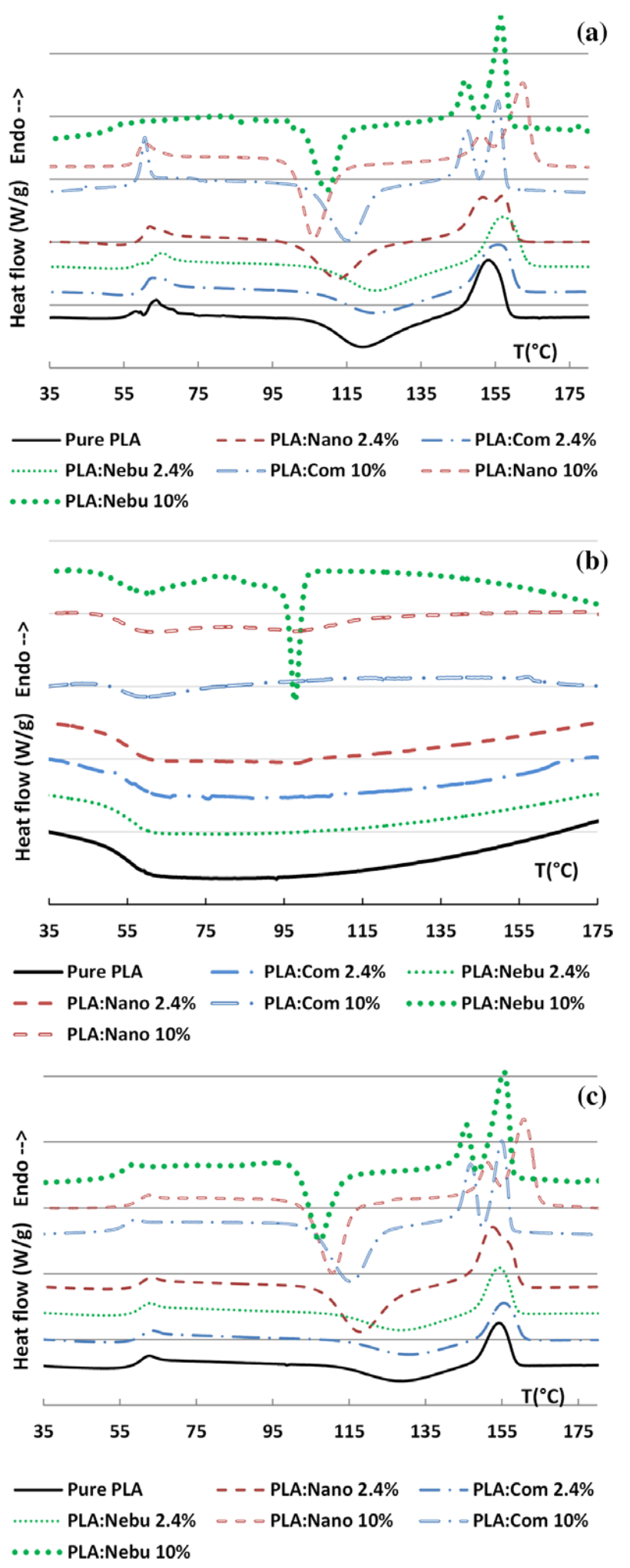

FIG. 4. First (a), second (c) heating and cooling (b) DSC scans for Pure PLA and PLA/chitosan films. [Color figure can be viewed at wileyonlinelibrary.com]

As seen in Fig. 4a and c, all thermograms show a heat flow variation between $55^{\circ} \mathrm{C}$ and $62^{\circ} \mathrm{C}$ corresponding to the glass transition $T_{\mathrm{g}}$ of PLA. It is noticeable that a marked endothermic phenomenon occurs at the glass transition, corresponding to the enthalpic relaxation of amorphous molecular chains of PLA. This phenomenon is more pronounced on the first heating scans especially for pure PLA and PLA:Com-10\% films, indicating that in these samples, PLA chains were frozen in a non-equilibrium conformational state during the cast-film extrusion process. The first melting, followed by the cooling at $10^{\circ} \mathrm{C} \cdot \mathrm{min}^{-1}$ under nonshearing conditions allow PLA chains to arrange in a more stable conformational state, explaining the reduced enthalpic relaxation observed in the second heating scans. No significant changes in the glass transition temperature $T_{\mathrm{g}}$ and in the melting temperatures $T_{\mathrm{m}}$ were observed between the first and second heating.

The exothermic peaks of cold-crystallization occurring during heating in DSC are shifted to higher temperatures for the second heating (the shift was more pronounced for pure PLA and for PLA/commercial chitosan at a loading rate of $2.4 \%$, around $10^{\circ} \mathrm{C}$ and $5^{\circ} \mathrm{C}$, respectively). It indicates that the supramolecular structure generated throughout the cast-film extrusion process induced an early cold-crystallization of PLA and PLA/chitosan films during the first heating in DSC. This result has to be related to the local orientation of PLA chains induced by the shearing upon extrusion that favor the growth of PLA crystals. These observations are also consistent with the marked enthalpic relaxation observed at the glass transition during the first heating scan, supporting that PLA chains were in a non-stable conformation and probably oriented state after extrusion. Peurton [30] also proposed this hypothesis to explain the presence of a cold-crystallization peak during the first heating scan of extruded PLA and its absence for non-extruded granulated PLA. In addition, the comparison of the degrees of crystallinity $\chi_{\mathrm{cf}}$ after the cold-crystallization $(E q .2)$ reveals that the orientation of the chains during the cast-extrusion process has a positive effect on the cold-crystallization of PLA; for instance, $\chi_{\mathrm{cf}}$ of Pure PLA was around $25.6 \%$ in the first heating against only $10.4 \%$ in the second heating.

The cast-film extrusion process is thus responsible for freezing PLA chains in a non-equilibrium conformational state within the films, probably oriented state, which is related to their low intrinsic molecular mobility. This was not strongly influenced by the chitosan particles regardless of their size and loading rate, but phenomena were more pronounced for pure PLA films with an earlier cold-crystallization for the first heating and a marked enthalpic relaxation at the $T_{\mathrm{g}}$.

\section{Effect of Chitosan Micro- and Nano-Particles.}

On the second heating scans (Fig. 4c), the only effect of chitosan particles on crystallization behavior of PLA was analyzed. The presence of $2.4 \%$ of chitosan particles did not seem to affect the glass transition temperature $T_{\mathrm{g}}$ of PLA (remaining $60^{\circ} \mathrm{C}$ to $61^{\circ} \mathrm{C} \pm$ $1^{\circ} \mathrm{C}$ ) for all the films regardless of the particle size. Nevertheless, a significant drop in the glass transition temperature was observed when the loading rate was increased up to $10 \%$, especially in the case of commercial chitosan and nebulized chitosan microparticles based PLA films $\left(56.2^{\circ} \mathrm{C} \pm 0.8^{\circ} \mathrm{C}\right.$ and $\left.54.2^{\circ} \mathrm{C} \pm 1.0^{\circ} \mathrm{C}\right)$. This drop in $T_{\mathrm{g}}$, sign of an higher molecular mobility of PLA chains, could be due to a reduction of chain length in the presence of high chitosan particles content. The molecular weights of PLA and its biocomposite films as measured by GPC are shown in Table 2. The average molecular weights $\overline{M w}$ and $\overline{M n}$ of PLA:Com-10\% and PLA:Nebu-10\% were three times lower than pure PLA film while they remained of the same order for PLA/Chitosan films at $2.4 \%$ loading rate and also for PLA:Nano-10\%. It should also be noted 
TABLE 1. Melting and crystallization enthalpies and temperatures, and degrees of crystallinity of pure PLA film and PLA/chitosan films measured on the first heating and second heating scans.

\begin{tabular}{|c|c|c|c|c|c|c|c|c|}
\hline Samples & $T_{\mathrm{cc}}\left({ }^{\circ} \mathrm{C}\right)$ & $\Delta H_{\mathrm{cc}}\left(\mathrm{J} \mathrm{g}^{-1}\right)$ & $T_{\mathrm{m} 1}\left({ }^{\circ} \mathrm{C}\right)$ & $T_{\mathrm{m} 2}\left({ }^{\circ} \mathrm{C}\right)$ & $\Delta H_{\mathrm{m}}\left(\mathrm{J} \cdot \mathrm{g}^{-1}\right)$ & $T_{\mathrm{g}}\left({ }^{\circ} \mathrm{C}\right)$ & $\chi_{\mathrm{c} 0}(\%)$ & $\chi_{\mathrm{cf}}(\%)$ \\
\hline \multicolumn{9}{|l|}{ First heating scan } \\
\hline Pure PLA & $119.1 \pm 0.2$ & $21.1 \pm 2.1$ & $152.9 \pm 0.1$ & - & $23.3 \pm 1.0$ & $60.9 \pm 0.0$ & $2.3 \pm 1.2$ & $25.6 \pm 1.1$ \\
\hline PLA:Com-2.4\% & $125.9 \pm 3.7$ & $19.7 \pm 0.5$ & $156.0 \pm 0.5$ & - & $20.1 \pm 2.6$ & $61.4 \pm 0.6$ & $0.5 \pm 0.5$ & $22.1 \pm 2.8$ \\
\hline PLA:Nebu- $2.4 \%$ & $125.7 \pm 2.8$ & $19.7 \pm 4.5$ & $155.7 \pm 1.2$ & - & $19.6 \pm 5.0$ & $59.7 \pm 0.7$ & $0.2 \pm 0.6$ & $21.5 \pm 5.5$ \\
\hline PLA:Nano- $2.4 \%$ & $111.7 \pm 0.9$ & $25.4 \pm 1.7$ & $153.8 \pm 1.2$ & $158.2 \pm 1.3$ & $27.5 \pm 0.3$ & $62.3 \pm 1.6$ & $2.2 \pm 1.5$ & $30.2 \pm 0.4$ \\
\hline PLA:Com-10\% & $115.1 \pm 0.0$ & $37.9 \pm 2.8$ & $146.9 \pm 0.1$ & $155.4 \pm 0.0$ & $38.2 \pm 2.8$ & $58.4 \pm 0.6$ & $0.4 \pm 0.1$ & $42.0 \pm 3.1$ \\
\hline PLA:Nebu-10\% & $107.3 \pm 2.3$ & $23.7 \pm 0.3$ & $146.6 \pm 0.6$ & $156.3 \pm 0.1$ & $28.7 \pm 0.5$ & $55.0 \pm 0.3$ & $6.0 \pm 1.4$ & $34.3 \pm 1.8$ \\
\hline PLA:Nano-10\% & $107.7 \pm 1.7$ & $34.2 \pm 0.0$ & $151.7 \pm 0.5$ & $162.3 \pm 0.2$ & $39.0 \pm 0.8$ & $58.7 \pm 1.4$ & $5.3 \pm 0.9$ & $42.9 \pm 0.9$ \\
\hline \multicolumn{9}{|c|}{ Second heating scan } \\
\hline Pure PLA & $129.3 \pm 1.8$ & $8.2 \pm 2.7$ & $154.4 \pm 0.2$ & - & $9.49 \pm 2.8$ & $60.1 \pm 0.7$ & $1.4 \pm 0.1$ & $10.4 \pm 3.1$ \\
\hline PLA:Com-2.4\% & $131.1 \pm 0.7$ & $12.4 \pm 1.0$ & $156.0 \pm 0.5$ & - & $12.9 \pm 0.5$ & $61.1 \pm 1.6$ & $0.6 \pm 0.6$ & $14.2 \pm 0.5$ \\
\hline PLA:Nebu-2.4\% & $129.5 \pm 1.6$ & $13.0 \pm 1.0$ & $156.0 \pm 1.7$ & - & $13.9 \pm 0.1$ & $61.0 \pm 0.3$ & $1.0 \pm 1.3$ & $15.3 \pm 0.2$ \\
\hline PLA:Nano- $2.4 \%$ & $118.9 \pm 0.9$ & $26.7 \pm 0.8$ & $153.8 \pm 1.2$ & $158.2 \pm 1.3$ & $28.5 \pm 0.2$ & $61.5 \pm 1.8$ & $2.0 \pm 1.1$ & $31.3 \pm 0.3$ \\
\hline PLA:Com-10\% & $115.4 \pm 0.2$ & $36.0 \pm 0.9$ & $146.8 \pm 0.0$ & $154.9 \pm 0.1$ & $36.1 \pm 1.0$ & $56.2 \pm 0.8$ & $0.2 \pm 0.1$ & $39.6 \pm 1.1$ \\
\hline PLA:Nebu-10\% & $105.5 \pm 1.5$ & $25.2 \pm 0.5$ & $145.4 \pm 0.3$ & $155.5 \pm 0.1$ & $28.5 \pm 1.3$ & $54.2 \pm 1.0$ & $3.8 \pm 2.2$ & $34.0 \pm 1.6$ \\
\hline PLA:Nano-10\% & $110.1 \pm 0.5$ & $31.2 \pm 1.2$ & $152.2 \pm 0.0$ & $160.6 \pm 0.1$ & $37.8 \pm 0.7$ & $58.9 \pm 0.1$ & $7.2 \pm 0.6$ & $41.5 \pm 0.8$ \\
\hline
\end{tabular}

that the cast-film extrusion process did not have any significant effect on the molecular weight of PLA in pure PLA films, which clearly evidences that the chosen processing parameters are nondegrading, and highlights the strong impact of high loading rates of commercial and nebulized chitosan microparticles in the reduction of PLA molecular weight. Indeed, high loading rates of particles induce a significant increase in shearing rate during the extrusion process, and hence a potential higher degradation of the material. Besides, impurities such as residual salt present in the commercial and nebulized chitosan microparticles could have had an effect on the molar mass reduction of PLA during film processing. On the other hand, the SCASA process allowed cleaning and purifying the chitosan nanoparticles [22].

Furthermore, two main differences were observed on the second heating thermograms depending on particle size and loading rate and related to the cold-crystallization and the melting peaks (Fig. 4c). The cold crystallization peak was narrower and shifted to lower temperatures as the particle size decreased and the loading rate increased, suggesting an earlier and sharper coldcrystallization of the PLA matrix in the presence of chitosan particles. The difference between PLA:Com 2.4\%, PLA:Nebu $2.4 \%$ and pure PLA films was not noticeable with a wide coldcrystallization peak around $130^{\circ} \mathrm{C}$ and low cold-crystallization enthalpies $\Delta H_{\mathrm{cc}}$ of 8.2 and $13.0 \mathrm{~J} . \mathrm{g}^{-1}$, respectively. In contrast with the study of Elsawy et al. [18], PLA: Nano-2.4\% showed a significant decrease of the cold-crystallization temperature $T_{c c}$ of

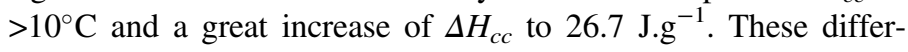
ences were even more pronounced when the particles loading increased to $10 \%$ with $\Delta H_{\mathrm{cc}}$ of $36.0,25.2$, and $31.2 \mathrm{J.g}^{-1}$ for PLA:Com-10\%, PLA:Nebu-10\% and PLA:Nano-10\%, respectively. These observations could originate from two main phenomena: the first would be the reduction of PLA chain length due to degradation in the presence of chitosan particles, which would favor molecular mobility and promote the cold-crystallization; the second would be a nucleating effect of chitosan particles, which would also lead to an earlier cold-crystallization. The molecular weight analysis presented above (Table 2) did not show any degradation of PLA chains due to the extrusion process nor to the presence of chitosan nanoparticles, supporting a pronounced nucleating effect of chitosan nanoparticles within the PLA matrix. In the presence of $10 \%$ commercial and nebulized chitosan microparticles, PLA chains degradation during the extrusion process was clearly evidenced ( $\overline{M w}$ divided by almost three), suggesting that this is the main reason of the early cold-crystallization for these films. It should be noticed an exothermic peak at $98{ }^{\circ} \mathrm{C}$, related to crystallization phenomenon, during the cooling scan (Fig. 4b) for the PLA:Nebu-10\% film that should be also due to the drastic PLA chains degradation favoring their crystallization.

Besides, PLA/chitosan films with $10 \%$ particle loading and PLA:Nano-2.4\% film presented two endothermic melting peaks while for Pure PLA, PLA:Com-2.4\% and PLA:Nebu-2.4\%, only one melting peak was observed. Several reasons may explain the presence of a double melting peak [30-32]: (1) the melting of two different coexisting crystallized structures ( $\alpha$ and $\beta)$, (2) the melting, within the same crystallized structure, of two crystal populations with different size, perfection and hence thermal stability

TABLE 2. Molecular weights (g.mol ${ }^{-\mathbf{1}}$ ) and polydispersity index (IP) of PLA granules, Pure PLA film and PLA/chitosan films, measured by GPC.

\begin{tabular}{|c|c|c|c|c|c|c|}
\hline Samples & $\overline{M w} \mathrm{~g} \cdot \mathrm{mol}^{-1}$ & $\overline{M n} \mathrm{~g} \cdot \mathrm{mol}^{-1}$ & $\overline{M v} \mathrm{~g} \cdot \mathrm{mol}^{-1}$ & $\overline{M p}$ g.mol ${ }^{-1}$ & $\overline{M z} \mathrm{~g} \cdot \mathrm{mol}^{-1}$ & $I P$ \\
\hline PLA granules & 163,937 & 92,135 & 151,992 & 131,173 & 253,241 & 1.8 \\
\hline Pure PLA (film) & 176,206 & 103,145 & 165,238 & 143,218 & 255,019 & 1.7 \\
\hline PLA:Com-2.4\% (film) & 133,732 & 71,587 & 124,140 & 112,542 & 204,416 & 1.9 \\
\hline PLA:Nebu-2.4\% (film) & 155,924 & 85,041 & 145,261 & 133,228 & 237,187 & 1.8 \\
\hline PLA:Com-10\% (film) & 58,666 & 29,510 & 54,085 & 50,350 & 93,083 & 2.0 \\
\hline PLA:Nebu-10\% (film) & 57,877 & 29,444 & 53,402 & 51,114 & 91,532 & 2.0 \\
\hline PLA:Nano-10\% (film) & 172,438 & 100,256 & 161,502 & 141,138 & 251,932 & 1.7 \\
\hline
\end{tabular}


(3) a melting-recrystallization-melting phenomenon induced by the formation of a first less thermally stable crystallized structure that melts at a lower temperature (first melting peak) followed by the recrystallization of a more perfect and stable crystalline structure that melts at a higher temperature (second peak). Stoclet [32] examined the crystal structure of PLA after extrusion by X-ray diffraction and only the $\alpha$ form appeared, which excludes the hypothesis of polymorphism. Many other authors interpreted the appearance of a double melting peak to the third hypothesis, melting-recrystallization-melting [26,30,33]. Yasuniwa et al. [26] studied the evolution of this double melting peak of PLA as a function of heating and cooling rates. They showed that fast cooling rates promote the generation of imperfect crystals while fast heating rates do not allow the recrystallization phenomenon after melting, thus inducing a single melting peak attributed to imperfect crystals. Due to this competition between melting and recrystallization, the recrystallization peak coincides with the melting peak for relatively rapid heating rates.

For these reasons, temperature-modulated DSC analysis was performed to separate the reversible thermal signal related to the melting and the irreversible signal related to the recrystallization upon the melting phase. On the reversible signal of PLA:Nano$2.4 \%$, two melting peaks and a shoulder on the first peak were clearly observed: a first strong peak between $140^{\circ} \mathrm{C}$ and $150^{\circ} \mathrm{C}$ and a second one of lower intensity between $150^{\circ} \mathrm{C}$ and $160^{\circ} \mathrm{C}$. On the non-reversible signal, a crystallization exothermic peak was located on the same temperature range as the first melting peak observed on the total heat flow and reversible signal, followed by an endothermic melting peak located at the same temperature as the second melting peak of the total heat flow and reversible signal. It should be noticed that the polymer characteristics and the acquisition parameters, especially the oscillation period, should influence the appearance of the melting peaks on the reversible or non-reversible signal. When the oscillation period is long enough for the melting to fully occur, the melting peak is only visible on the reversible signal, which was the case for the first melting peak. In contrast, the second melting peak was visible on both reversible and non-reversible signals. All PLA biocomposite films at $2.4 \%$ and $10 \%$ loading rate exhibited the same behavior in temperature-modulated DSC, which confirms the occurrence of a melting-recrystallization-melting

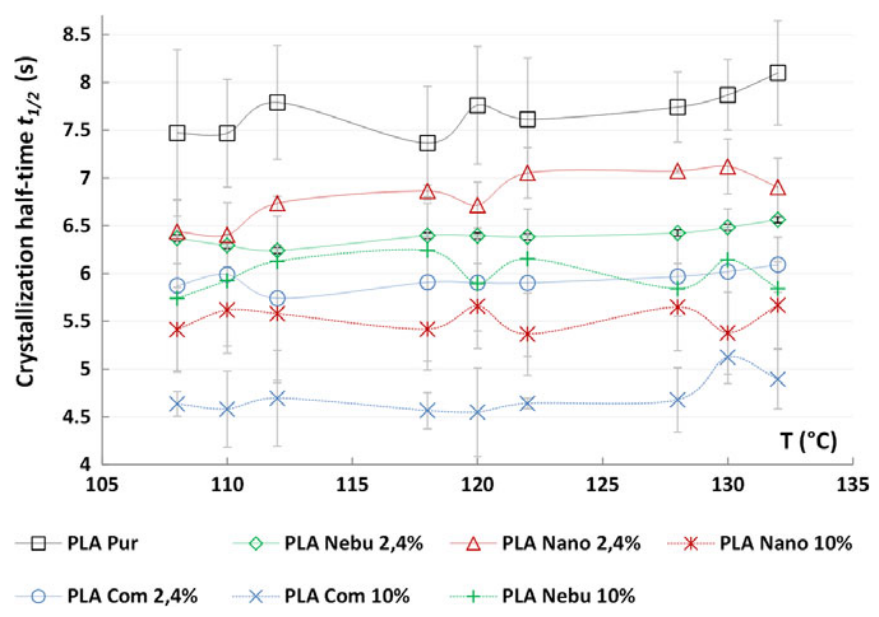

FIG. 5. Crystallization half-time $t_{1 / 2}$ at different isothermal crystallization temperatures for pure PLA and PLA/chitosan films. [Color figure can be viewed at wileyonlinelibrary.com] phenomenon related to the early melting of imperfect crystals formed during the cold-crystallization. Peurton [30] and Gerard and Budtova [34] also reported that this phenomenon is more pronounced when the difference between the cold-crystallization temperature and the melting temperature increases. This may explain the appearance of more pronounced double melting peaks on thermograms of PLA:Nano-2.4\% and PLA films with $10 \%$ loading rate $\left(\Delta T \sim 31^{\circ} \mathrm{C}-42^{\circ} \mathrm{C}\right.$ between $T_{\mathrm{cc}}$ and $\left.T_{\mathrm{f}}\right)$, and its absence for pure PLA and PLA:Com-2.4\% and PLA:Com-2.4\% films $\left(\Delta T \sim 26^{\circ} \mathrm{C}\right)$.

Finally, the degree of crystallinity $\chi_{\mathrm{cf}}(E q .2)$ determined from the second heating scan was significantly increased by the addition of $2.4 \%$ chitosan nanoparticles in PLA compared with pure PLA film (31.3\% vs. $10.4 \%)$ whereas the commercial and nebulized microparticles did not have a significant effect (Table 1). For $10 \%$ loading rate, $\chi_{\mathrm{cf}}$ was even more higher for PLA:Nano, PLA:Nebu and PLA:Com films $(41.5 \%, 34.0 \%$, and $39.6 \%$, respectively). Furthermore, the differences in degree of crystallinity $\chi_{\text {cf }}$ between the first and second heating scan for chitosan nanoparticles based films and films at $10 \%$ loading rate was negligible, highlighting the preponderant effect of chitosan particles on the cold-crystallization over the chain orientation effect induced by the cast-extrusion process. As discussed earlier, this has to be related to the nucleating effect of chitosan nanoparticles in the case of PLA:Nano films, and the strong degradation of PLA chains in the case of commercial and nebulized chitosan microparticles in PLA:Com-10\% and PLA:Nebu-10\% films.

\section{Isothermal Crystallization Behavior of PLA and PLA/Chitosan Biocomposites}

To evaluate the effect of chitosan micro- and nano-particles on PLA crystallization kinetics, successive isothermal cycles were applied, starting from the molten state followed by a very fast cooling to reach the isothermal crystallization temperature and avoid any premature crystallization. In this part of the study, crystal growth kinetics after the activation of the first germs was investigated and not the germination kinetics. This means that the initial time considered $(t=0)$ corresponds to the beginning of the crystallization when the germs start growing. All the studied PLA biocomposite films presented similar isothermal crystallization curves and the recorded crystallization time was not $>30$ s. The evolution of the volume fraction transformed into crystals as function of time $\alpha(t)$ was determined by integrating the areas of the crystallization peaks. The shape of $\alpha(t)$ curves clearly showed differences in the crystallization kinetics according to the different PLA/chitosan films and isothermal crystallization temperatures.

Based on these observations, the characteristic crystallization half-time $t_{1 / 2}$ corresponding to $50 \%$ of transformed crystals was determined for each sample and isotherm so as to evaluate variations in crystallization kinetics (Fig. 5). Despite the wide temperature range studied $\left(108^{\circ} \mathrm{C}-132^{\circ} \mathrm{C}\right)$, the isothermal crystallization temperature did not appear to have a significant effect on $t_{1 / 2}$ for a given type or loading rate of chitosan particles. However, the presence of chitosan micro- and nano-particles in PLA had a significant effect on its crystallization kinetics, i.e. chitosan particles greatly reduced $t_{1 / 2}$, and hence increased the crystal growth rate of PLA crystals, particularly when the loading rate increased. Moreover, the size of chitosan particles impacted the crystallization kinetics. Commercial and nebulized chitosan microparticles 

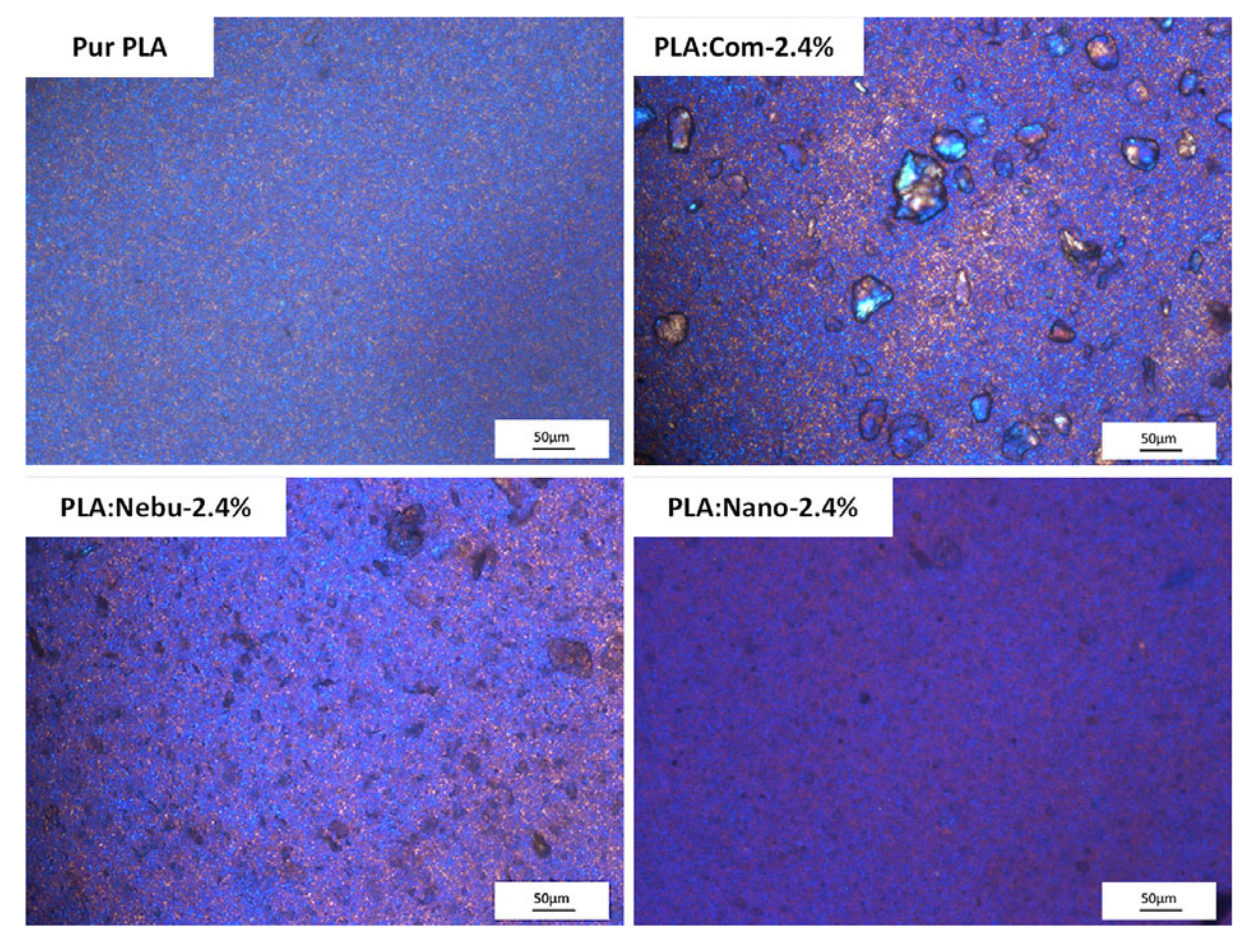

FIG. 6. Optical microscopy observations under cross polarized light with a gypsum plate of crystals formation during isothermal crystallization at $120^{\circ} \mathrm{C}$ of Pure PLA and PLA films loaded at $2.4 \%$ of chitosan micro- and nano-particles. [Color figure can be viewed at wileyonlinelibrary.com]

appear to promote crystal growth rate more than chitosan nanoparticles. This can be explained by the state of dispersion of chitosan particles within the PLA matrix. Indeed, despite the pronounced nucleating effect of chitosan nanoparticles observed previously, inducing faster germination, the greater specific surface area and fine dispersion developed with these nanoparticles could restrict the mobility of PLA chains and hence slow down the growth of PLA crystals. In contrast, the dispersion of commercial and nebulized microparticles leaves larger areas free of particles where the molecular mobility is not impacted; and thus not impeding crystal growth. On the other hand, in the case of commercial and nebulized chitosan microparticles at $10 \%$ loading rate, the drastic degradation of PLA chains upon processing, resulting in an enhanced molecular mobility, may be also responsible for the higher crystal growth rate compared with the PLA:Nano films for which the molecular characteristics of PLA remained unchanged.

The crystallization mode $n$ (Avrami exponent) and the rate constant $k$ of the isothermal transformation were determined from the linear expression of the Avrami-Evans law (Eq. 4). $n$ and $\ln k$ are respectively the slope coefficient and the intercept of the $\ln [-\ln$ $(1-\alpha(t))]$ curve versus $\ln (t)$. The resulting plots showed parallel straight lines for the different biocomposite films and similar slopes with an Avrami exponent $n$ close to 2 . This means that chitosan particles, regardless of their size or loading rate, did not affect the crystal growth mode of PLA. According to Avrami's theory, the coefficient $n$ is an integer value in two limit cases: (1) sporadic germination; (2) instantaneous germination. In isothermal conditions, the value of 2 corresponds either to sporadic germination of rod-like crystals where germs are enabled throughout the crystallization or to instantaneous germination of discs shaped crystals where germs are simultaneously activated at the beginning of the crystallization. Additional optical microscopy observations under polarized light of the isothermal crystallization of PLA and its biocomposites at $120^{\circ} \mathrm{C}$ were conducted to study the nucleation process and the crystals shape. Pictures in Fig. 6 were recorded $150 \mathrm{~s}$ after the beginning of the isotherm. Unfortunately, the germs and resulting crystals were too small to draw conclusions but we assume that instantaneous germination of discs is the most likely mode of growth, since the germination of rod-like crystals of PLA in these standard isothermal crystallization conditions were not described in the literature.

Besides, significant differences in the crystallization rate constant $\mathrm{k}$ values were noticed, ranging from $25 \pm 1$ to $34 \pm$ $1 \mathrm{~min}^{-1}$ for Pure PLA (from $132^{\circ} \mathrm{C}$ to $108^{\circ} \mathrm{C}$ ) and reaching up to $85 \mathrm{~min}^{-1}$ for formulations that crystallize faster. Indeed, it was observed that $k$ increases with higher loading rates of chitosan, hence implying an increase in the crystals growth rate of PLA in the presence of chitosan. These experimental results were in accordance with the theoretical values of $k$ calculated from the values of $t_{1 / 2}$ by $E q .5$, and are thus consistent with the significant decrease of the crystallization half-time $t_{1 / 2}$ already observed for PLA/chitosan films at high loading rates.

\section{CONCLUSIONS}

In this study, chitosan nanoparticles generated by an organic-solvent-free supercritical $\mathrm{CO}_{2}$ assisted process (SCASA) and chitosan microparticles were dispersed in PLA by cast-film extrusion using a twin screw micro-compounder. The microstructure and thermal properties of the resulting PLA/chitosan biocomposite films were studied for two particle loading rates $(2.4 \%$ and $10 \% \mathrm{w} / \mathrm{w})$. Dispersion and size distribution of chitosan micro- and nano-particles in the films were analyzed by optical microscopy and laser diffraction. Results showed a homogeneous dispersion of the particles with no 
agglomeration, due to favorable physico-chemical interactions between chitosan particles and PLA and weak particle cohesion within the agglomerates. Non-isothermal DSC experiments revealed a pronounced nucleating effect as well as a great enhancement of the degree of crystallization of PLA in the presence of chitosan particles. Besides, GPC experiments revealed that no degradation of PLA molecular characteristics occurred with chitosan nanoparticles. The effect of chitosan particles on the crystallization kinetics of PLA films was studied by isothermal analysis. It was observed that PLA crystal growth rate was enhanced by the presence of chitosan microand nano-particles, especially at high loading rates. The addition of chitosan nanoparticles in PLA thus appears to be an efficient way to favor and enhance its crystallization without degrading PLA molecular characteristics. This could possibly bypass other processing and formulation strategies developed to control PLA crystallization.

\section{ACKNOWLEDGMENTS}

This paper is dedicated to the memory of our esteemed colleague Elisabeth Rodier, who left us much too early. The authors thank Laurent David (IMP) and Vincent Lapinte (ICGM) for the GPC analyzes on chitosan and PLA grades used in this study.

\section{REFERENCES}

1. M. Chauvet, M. Sauceau, and J. Fages, J. Supercrit. Fluids., 120, 408 (2017).

2. I. Armentano, N. Bitinis, E. Fortunati, S. Mattioli, N. Rescignano, R. Verdejo, M.A. Lopez-Manchado, and J. M. Kenny, Prog. Polym. Sci., 38, 1720 (2013).

3. G.L. Loomis, J.R. Murdoch, U.S. Patent, 4,902,515 (1990).

4. M.M. Reddy, S. Vivekanandhan, M. Misra, S.K. Bhatia, and A. K. Mohanty, Prog. Polym. Sci., 38, 1653 (2013).

5. S. Saeidlou, M.A. Huneault, H. Li, and C.B. Park, Prog. Polym. Sci., 37, 1657 (2012).

6. R.M. Rasal, A.V. Janorkar, and D.E. Hirt, Prog. Polym. Sci., 35, 338 (2010).

7. J.-M. Raquez, Y. Habibi, M. Murariu, and P. Dubois, Prog. Polym. Sci., 38, 1504 (2013).

8. S. Sinha Ray, K. Yamada, M. Okamoto, and K. Ueda, Polymer, 44, 857 (2003).

9. S.S. Ray, K. Yamada, M. Okamoto, and K. Ueda, Macromol. Mater. Eng., 288, 203 (2003).

10. A.J. Svagan, A. Åkesson, M. Cárdenas, S. Bulut, J. Knudsen, J. C. Risbo, and D. Plackett, Biomacromolecules, 13, 397 (2012).

11. E. Petinakis, X. Liu, L. Yu, C. Way, P. Sangwan, K. Dean, S. Bateman, and G. Edward, Polym. Degrad. Stab., 95, 1704 (2010).

12. M. Chauvet, M. Sauceau, F. Baillon, and J. Fages, J. Appl. Polym. Sci., 134, 45067 (2017).
13. A. Pei, Q. Zhou, and L.A. Berglund, Compos. Sci. Technol., 70, 815 (2010).

14. F.A. dos Santos, G.C.V. Iulianelli, and M.I.B. Tavares, Polym. Test., 61, 280 (2017).

15. M. Jonoobi, J. Harun, A.P. Mathew, and K. Oksman, Compos. Sci. Technol., 70, 1742 (2010).

16. J. Bonilla, E. Fortunati, M. Vargas, A. Chiralt, and J.M. Kenny, J. Food Eng., 119, 236 (2013).

17. V.M. Correlo, L.F. Boesel, M. Bhattacharya, J.F. Mano, N. M. Neves, and R.L. Reis, Mater. Sci. Eng. A., 403, 57 (2005)

18. M.A. Elsawy, G.R. Saad, and A.M. Sayed, Polym. Eng. Sci., 56, 987 (2016).

19. G. Crini, P.-M. Badot, and E. Guibal, Chitine et chitosane : Du biopolymére á l'application, Presses Universitaires de Franche-Comté (2009).

20. E. Guibal, Prog. Polym. Sci., 30, 71 (2005).

21. K.V. Harish Prashanth and R.N. Tharanathan, Trends Food Sci. Technol., 18, 117 (2007).

22. N. Hijazi, E. Rodier, J.-J. Letourneau, H. Louati, M. Sauceau, N. Le Moigne, J.-C. Benezet, and J. Fages, J. Supercrit. Fluids., 95, 118 (2014).

23. M. Jaworska, K. Sakurai, P. Gaudon, and E. Guibal, Polym. Int., 52, 198 (2003).

24. E.W. Fischer, H.J. Sterzel, and G. Wegner, Kolloid-Zeitschrift und Zeitschrift für Polym, 251, 980 (1973).

25. L.M.W.K. Gunaratne and R.A. Shanks, Thermochim. Acta., 430, 183 (2005).

26. M. Yasuniwa, S. Tsubakihara, Y. Sugimoto, and C. Nakafuku, J. Polym. Sci. Part B Polym. Phys., 42, 25 (2004).

27. V. Khoshkava and M.R. Kamal, Biomacromolecules., 14, 3155 (2013).

28. D.K. Owens and R.C. Wendt, J. Appl. Polym. Sci., 13, 1741 (1969).

29. A.G. Cunha, S.C.M. Fernandes, C.S.R. Freire, A.J. D. Silvestre, C.P. Neto, and A. Gandini, Biomacromolecules., 9, 610 (2008).

30. F. Peurton, Nanocomposites à matrice thermoplastique et renforts plaquettaires: relations élaboration-structure-propriétés, Doctoral dissertation (2008) (available from http://ori. univ-lille1.fr/notice/view/univ-lille1-ori-10288.

31. Y.-T. Shieh and G.-L. Liu, J. Polym. Sci. Part B Polym. Phys., 45, 466 (2007).

32. G. Stoclet, Étude de la structuration à différents niveaux d'échelle et du comportement thermomécanique d'un polymère issu de ressources renouvelables : l'acide poly(lactique), Doctoral dissertation (2009) (available from http://ori.univlille1.fr/notice/view/ univ-lille1-ori-8524).

33. Z. Kulinski and E. Piorkowska, Polymer, 46, 10290 (2005).

34. T. Gerard and T. Budtova, Eur. Polym. J., 48, 1110 (2012). 